\title{
Anatomia visceral comparada de seis espécies de Amphisbaenidae (Squamata: Amphisbaenia)
}

\author{
Maria Eliana C. Navega-Gonçalves
}

\begin{abstract}
Faculdade de Ciências Exatas e da Natureza, Universidade Metodista de Piracicaba. Rodovia do Açúcar, km 156, Taquaral, 13400-911 Piracicaba, São Paulo, Brasil. E-mail: eliana_navega@ig.com.br
\end{abstract}

\begin{abstract}
Comparison of visceral anatomy of six species of Amphisbaenidae (Squamata: Amphisbaenia). Visceral anatomy of amphisbaenids Amphisbaena vermicularis Wagler, 1824; Anops kingii Bell, 1833; Aulura anomala Barbour, 1914; Bronia bedai Vanzolini, 1991; Cercolophia cuiabana Strüssmann \& Carvalho, 2001, and Leposternon microcephalum Wagler, 1824 were comparatively described and the size and the position of the organs in the pleuroperitoneal cavity was established in relation to the ventral scutellation. The main results were: the right lung presents different degrees of size reduction compared to the left lung, being conspicuous only in A. anomala, and L. microcephalum; the limit between small and large intestines is clear due to the presence of a caecum; the right lobe of the liver is larger than the left one, but its length varies within the same species and among species; the right gonad occupies a more cranial position in relation to the left one, in all six studied species; the right ovary is also larger than the left one in all studied specimens, whereas the left testicle can be larger or of the same size as the right one in some specimens; the shape of the testicles varies from elongated, kidney-shaped or oval; kidneys are symmetrically positioned at the caudal portion of the pleuroperitoneal cavity and one kidney can be larger than the other.
\end{abstract}

KEY WORDS. Alimentary tract; amphisbaenians; gonads; kidneys; lungs.

Os Amphisbaenia Gray, 1844 são répteis fossoriais que apresentam marcantes especializações para a vida subterrânea. O corpo é alongado e cilíndrico e a maioria das espécies é ápode (GANs 1968, 1969).

Um total de 190 espécies estão agrupadas em quatro famílias tradicionalmente reconhecidas: Bipedidae Taylor, 1951anfisbênios com membros anteriores desenvolvidos, com um único género, Bipes Latreille, 1802, e três espécies no México; Rhineuridae Vanzolini, 1951 com apenas uma espécie recente, Rhineura floridana Baird, 1858 na Florida-EUA; Trogonophidae Vanzolini, 1951 com quatro gêneros (Agamodon Peters, 1882; Diplometopon Nikolski, 1907; Pachycalamos Günther, 1881 e Trogonophis Kaup, 1830) e oito espécies na África e no Oriente Médio; e Amphisbaenidae Gray, 1865, com 18 gêneros e cerca de 178 espécies na África, América Central, América do Sul e Caribe (Kearney 2003, Gans 2005).

Estudos filogenéticos recentes, no entanto, apontam duas novas famílias: Blanidae Kearney, 2003 e Cadeidae Vidal \& Hedges, 2008 cujas espécies eram incluídas entre os Amphisbaenidae. A primeira, com seis espécies pertencentes ao gênero Blanus Wagler, 1830 (na região Mediterrânea) e a segunda, com duas espécies do gênero Cadea Gray, 1844, em Cuba (Kearney 2003, VIDAL et al. 2008).

Os primeiros estudos a fornecerem informações sobre a anatomia visceral de Amphisbaenia datam do século XIX e iní- cio do século XX, e constituem estudos clássicos de anatomia, que primam pela riqueza de descrições (Duvernoy 1833, RATHKE 1857, Bedriaga 1884, Smalian 1884, Butler 1889, 1895, Cope 1896, LÖNNBERg 1902, BEDDARD 1905, JACOBSHAGEN 1920). Em trabalhos mais recentes, aspectos diversos da anatomia visceral destes animais foram descritos, tais como: a morfologia do canal alimentar (Parsons \& Cameron 1977, Navega-Gonçalves \& Souza 2003), do fígado e das vias biliares (De Carlo 1957), do pâncreas (Miller \& Lagios 1970), da cloaca e dos órgãos urogenitais (Bons \& SAINT Girons 1963, Gabe \& SaINT Girons 1965), bem como do coração e dos arcos arteriais (FrANCIS 1977, Renous 1985). No entanto, apenas um estudo detalhado da anatomia visceral foi realizado de forma comparativa em dezesseis espécies, pertencentes às quatro famílias até então reconhecidas (Crook \& PARsons 1980) e serviu de base para as análises e comparações neste estudo.

Vários aspectos da biologia dos Amphisbaenia ainda permanecem desconhecidos, em parte porque os hábitos fossórios destes animais dificultam as coletas e restringem as observações na natureza. Sendo assim, este estudo tem como objetivo descrever e comparar a anatomia visceral de seis espécies de Amphisbaenidae: Amphisbaena vermicularis Wagler, 1824; Anops kingii Bell, 1833; Aulura anomala Barbour, 1914; Bronia bedai Vanzolini, 1991; Cercolophia cuiabana Strüssmann \& Carvalho, 2001 e Leposternon microcephalum Wagler, 1824, visando contribuir para um maior conhecimento do grupo. 


\section{MATERIAL E MÉTODOS}

Foram examinados um total de 38 exemplares de anfisbenídeos, pertencentes às espécies: $A$. vermicularis, $A$. kingii, $A$. anomala, B. bedai, C. cuiabana e L. microcephalum, cujos dados relativos à procedência, sexo, comprimento total e massa de cada espécime constam na tabela I. A maior parte do material foi emprestada de coleções zoológicas do Museu Nacional do Rio de Janeiro (MNRJ), Museu de Ciências e Tecnologia da PUCRS (MCP) e Museu Paraense Emilio Goeldi (MPEG). Alguns exemplares vieram de resgates de fauna de aproveitamentos hidrelétricos de Serra da Mesa (Minaçu, Goiás), de Corumbá (Corumbá, Goiás) e de Manso (Chapada dos Guimarães, Mato Grosso) e doados para este fim. Outros foram doados diretamente à Universidade de São Paulo. Os espécimes doados foram identificados com a sigla IBDZ (Instituto de Biociências, Departamento de Zoologia) seguida da abreviação do nome da espécie (AV, BB, CC, LM) e de um número (indicativo do exemplar referente à espécie). Este procedimento foi utilizado com o objetivo de identificar os espécimes, cujas características distintas foram citadas ao longo do trabalho.

Do total de espécimes examinados, apenas três foram recebidos vivos (IBDZAV-01, IBDZLM-10 e IBDZLM-11) e mantidos em terrários até serem eutanasiados. Para este procedimento utilizou-se Ketamina $50 \mathrm{mg}$ via intramuscular, na região ventral do corpo, na proporção de 2,5 mg/100 g, com base em Cooper (1992) e Massone (1999). Posteriormente foram fixados com paraformoldeído a $4 \%$.

Com o intuito de facilitar as comparações intra e interespecíficas, estabeleceu-se a posição dos órgãos internos em relação à escutelação ventral (sintopia). Para tanto, as contagens dos anéis do corpo foram feitas de acordo com a metodologia adotada para este fim: GaNs (1971) para Leposternon e Gans \& Alexander (1962) para as demais. Os anéis foram marcados com alfinetes e posteriormente com linha, antes de se proceder à dissecção do animal. Dados anatômicos foram colhidos de todos os espécimes referidos, no entanto, a sintopia dos diversos órgãos só foi estabelecida nos exemplares intactos e em bom estado de fixação (total de 30 espécimes). Considerou-se para cada órgão sua posição inicial e final em relação aos anéis ventrais, obtendo-se assim a extensão do órgão em número de anéis. Os comprimentos dos pulmões direito e esquerdo foram medidos com paquímetro e calculou-se a percentagem do pulmão direito em relação ao esquerdo, para cada espécie. Calculou-se também a proporção ocupada pelo pulmão esquerdo em relação à cavidade pleuroperitoneal, baseado nos dados de sintopia. Os demais órgãos pares: ovários, testículos e rins também foram medidos, para que pudessem ser comparados entre si e entre os espécimes, uma vez que os dados de sintopia nem sempre evidenciam diferenças com relação ao tamanho dos órgãos. A cavidade pleuroperitoneal foi dividida em terços cranial, médio e caudal, de acordo com a média dos anéis do corpo para cada espécie, com o intuito de facilitar as descrições anatômicas e as comparações intra e interespecíficas. Informações sobre a cor dos órgãos foram obtidas principalmente dos espécimes recém-eutanasiados, uma vez que os métodos de conservação podem alterar a coloração dos mesmos.

Devido ao pequeno tamanho da amostra para cada espécie, não foram realizadas análises estatísticas e as comparações foram feitas individualmente, quando necessário.

O material foi examinado sob estereomicroscópio ZEISSSV6 e fotografado com câmara fotográfica Pentax K1000 e LEICA WILD MPS52. Os desenhos foram feitos pelo desenhista Cavani Rosas.

\section{RESULTADOS}

Os dados referentes à sintopia dos órgãos presentes na cavidade pleuroperitoneal em relação à escutelação ventral constam nas tabelas II a VII, para cada uma das seis espécies consideradas neste estudo.

Os órgãos alojados na cavidade pleuroperitoneal são, em sua maioria, alongados e estão caracteristicamente dispostos de forma a se adequar em um corpo longo e cilíndrico. Os órgãos pareados, por sua vez, tendem a sofrer redução ou deslocamento unilateral, em maior ou menor grau (Fig. 1).

A traquéia é um tubo longo e transparente formado por anéis cartilaginosos, em forma de ferradura. É ventral ao esôfago e está unida a este pela lâmina esofágica-traqueal. A traquéia dispõe-se ao longo da linha mediana ventral do corpo, no terço cranial da cavidade pleuroperitoneal(Fig. 1). Na região do coração, localiza-se dorsal a este e penetra no pulmão esquerdo, sem ramificar-se (Figs 2 e 3 ).

Apenas o pulmão esquerdo está totalmente desenvolvido e caracteriza-se como um órgão alongado, saculiforme e de aspecto esponjoso, em sua porção cranial e, reticuloso em sua porção caudal. Estende-se da porção caudal do coração, no terço cranial da cavidade pleuroperitoneal, até a região mediana do fígado, no terço médio da cavidade pleuroperitoneal. Prende-se ao estômago e ao fígado através dos ligamentos mesentéricos pulmogástrico e pulmo-hepático, respectivamente. A metade cranial do pulmão é macroscopicamente mais rica em subdivisões internas (septos ou trabéculas), quando comparada à metade caudal, que se assemelha a um saco semi-transparente (Figs1-3).

De acordo com os dados de sintopia obtidos (Tabs II-VII) o pulmão esquerdo é respectivamente maior nas espécies: $A$. kingii, L. microcephalum, A. anomala, A. vermicularis, C. cuiabana e $B$. bedai.

O pulmão direito, quando presente, está consideravelmente reduzido nas espécies examinadas. No entanto, o grau de redução varia interespecificamente. Em A. anomala e $L$. microcephalum, o pulmão direito é um órgão com limites definidos, separado do pulmão esquerdo pela porção caudal do tubo traqueal (brônquio), ao qual se comunica através de um orifício em A. anomala (Fig. 3) e de dois orifícios em L. microcephalum (Fig. 4). O pulmão direito equivale a 7,5\% e 9,2\% do pulmão 


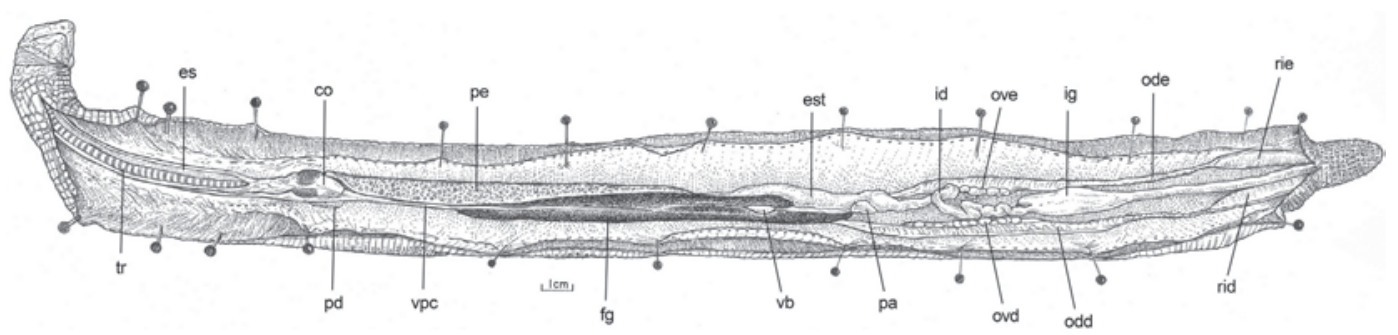

Figura 1. Leposternon microcephalum: morfologia interna da cavidade pleuroperitoneal, em vista ventral, mostrando a disposição das vísceras. (co) coração, (es) esôfago, (est) estômago, (fg) fígado, (id) intestino delgado, (ig) intestino grosso, (ovd) ovário direito, (ove) ovário esquerdo, (odd) oviduto direito, (ode) oviduto esquerdo, (pa) pâncreas, (pd) pulmão direito, (pe) pulmão esquerdo, (rid) rim direito, (rie) rim esquerdo, (tr) traquéia, (vb) vesícula biliar, (vpc) veia pós-cava. Bexiga e tecido adiposo retirados. Barra de escala $=1 \mathrm{~cm}$.
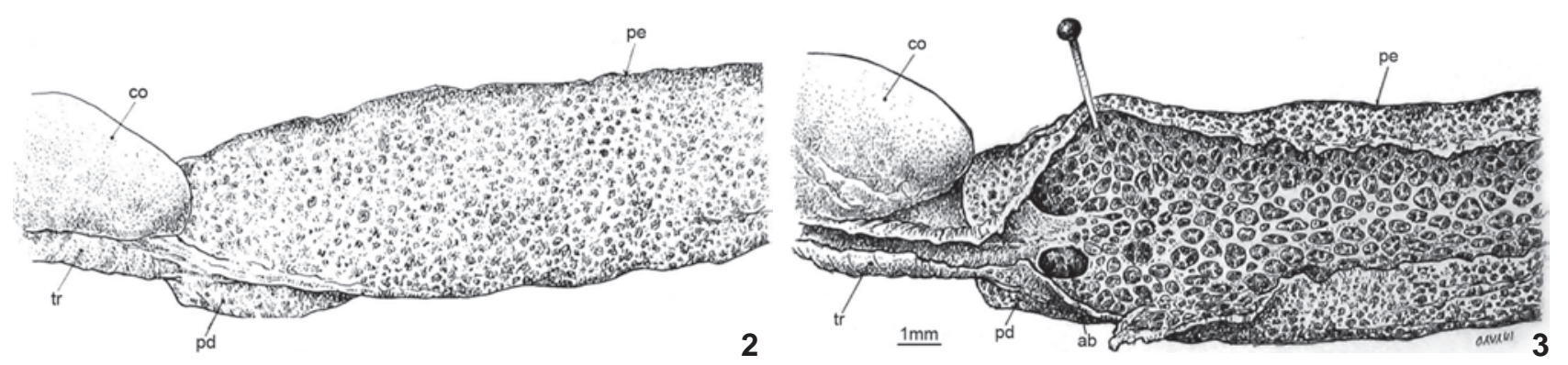

Figuras 2-3. Aulura anomala: (2) morfologia externa do pulmão direito e da porção cranial do pulmão esquerdo, em vista ventral; (3) pulmão esquerdo seccionado longitudinalmente, em vista ventral, mostrando orifício único de comunicação com o pulmão direito reduzido. (ab) abertura bronquial, (co) coração, (pd) pulmão direito, (pe) pulmão esquerdo, (tr) traquéia. Barra de escala = 1 mm.

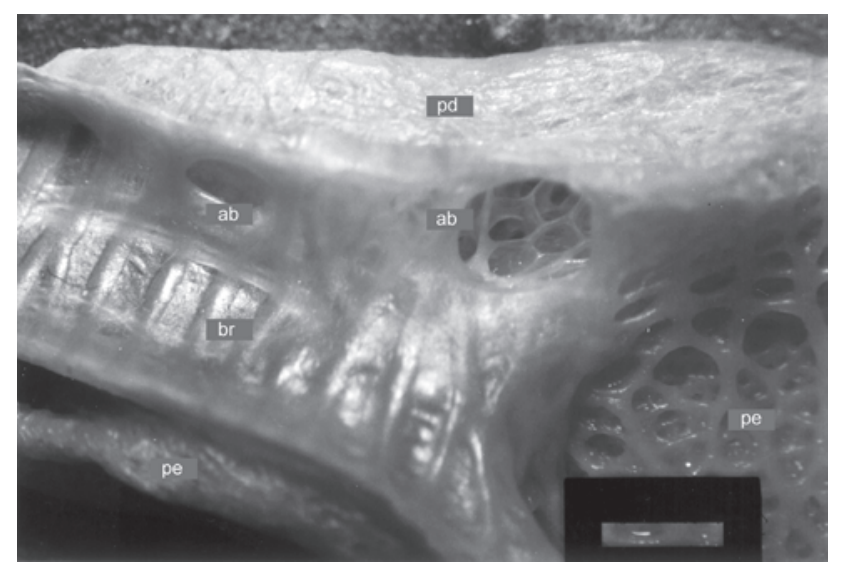

Figura 4. Leposternon microcephalum: morfologia interna da porção caudal da traquéia (brônquio) e pulmão esquerdo seccionados longitudinalmente, em vista dorsal. (ab) abertura bronquial, (br) brônquio, (pd) pulmão direito não seccionado, (pe)pulmão esquerdo. Barra de escala $=1,67 \mathrm{~mm}$.

esquerdo, em comprimento, em A. anomala e L. microcephalum, respectivamente (Tab. VIII). Em $A$. vermicularis o pulmão direito é muito reduzido, podendo ser considerado um órgão rudimen- tar, pois não se caracteriza como um órgão definido, mas como um tecido pulmonar difuso localizado látero-dorsalmente à porção caudal do tubo traqueal. Em C. cuiabana, o pulmão direito foi observado em apenas um espécime, também como um tecido pulmonar difuso. Em B. bedai, o pulmão direito não foi identificado em nenhum dos espécimes examinados. Em A. kingii o pulmão direito só foi visualizado em um dos espécimes examinados (A. kingii MCP-4735): de formato oval e medindo aproximadamente $2 \mathrm{~mm}$ de comprimento, encontra-se láterodorsalmente à porção caudal do tubo traqueal. Proporcionalmente, equivale a $4,6 \%$ do pulmão esquerdo em comprimento (Tab. VIII). Nenhum orifício de comunicação do tubo traqueal com o pulmão direito foi observado neste exemplar.

O coração é um órgão piriforme constituído pelo seio venoso, dois átrios e um ventrículo, envoltos pelo pericárdio. Situa-se na extremidade caudal do terço cranial da cavidade pleuroperitoneal, crânio-ventralmente ao pulmão esquerdo. Os átrios são alongados, sendo o direito maior que o esquerdo. A extremidade caudal do ventrículo está ligeiramente voltada para a direita da cavidade do corpo (Figs 1-3).

O esôfago é um tubo muscular cilíndrico, longo e retilíneo, dorsal à traquéia e unido a esta pela lâmina mesentérica esofágicatraqueal e à parede da cavidade pleuroperitoneal pela porção esofagial do mesentério dorsal. Ocupa o terço cranial e médio 
Tabela I. Dados relativos aos 38 espécimes de Amphisbaenidae utilizados para a realização dos estudos de anatomia visceral e sintopia dos órgãos internos em relação à escutelação ventral. Comprimento total em centímetros (C.T.); massa em gramas; * indica espécime com cauda autotomizada. Amphisbaena vermicularis $(n=9$; comprimento $=29,3 \pm 2,4$ de desvio padrão; massa $=14,0 \pm 3,0$ de desvio padrão), A. kingii $(n=7$; comprimento $=21,5 \pm 1,9 ;$ massa $=5,2 \pm 1,5)$, Aulura anomala $(n=5 ;$ comprimento $=26,4 \pm 2,2 ;$ massa $=17,9$ $\pm 4,5)$, Bronia bedai $(n=4$; comprimento $=25,0 \pm 6,7$; massa $=7,7 \pm 5,1)$, Cercolophia cuiabana $(n=5 ;$ comprimento $=21,5 \pm 4,0 ;$ massa $=3,1 \pm 1,0)$ e Leposternon microcephalum ( $n=8$; comprimento $=40,8 \pm 4,5$; massa $=53,7 \pm 18,9)$. (IBDZ) Instituto de Biociências, Departamento de Zoologia; (MNRJ) Museu Nacional do Rio de Janeiro; (MCP) Museu de Ciências e Tecnologia da PUCRS; (MPEG) Museu Paraense Emilio Goeldi Total de 38 espécimes.

\begin{tabular}{|c|c|c|c|c|}
\hline Espécie/número coleção & Procedência & Sexo & C.T. $(\mathrm{cm})$ & Massa $(g)$ \\
\hline A. vermicularis IBDZAV-01 & Minaçu-GO & Fêmea & 31,6 & 13,7 \\
\hline A. vermicularis MNRJ-7086 & Manga-MG & Fêmea & $26,1^{*}$ & 10,6 \\
\hline A. vermicularis MNRJ-7087 & Manga-MG & Macho & 30,1 & 15,3 \\
\hline A. vermicularis MNRJ-7088 & Manga-MG & Macho & $27,2^{*}$ & 12,7 \\
\hline A. vermicularis MNRJ-7089 & Manga-MG & Macho & 29,5 & 13,8 \\
\hline A. vermicularis MNRJ-7090 & Manga-MG & Fêmea & $31,1^{*}$ & 18,0 \\
\hline A. vermicularis MNRJ-7091 & Manga-MG & Fêmea & $29,1^{*}$ & 14,1 \\
\hline A. vermicularis MNRJ-7092 & Manga-MG & Fêmea & 26,2 & 9,4 \\
\hline A. vermicularis MNRJ-7093 & Manga-MG & Macho & 32,6 & 18,2 \\
\hline Anops kingii MCP-1240 & Novo Hamburgo-RS & Fêmea & 21,1 & 3,7 \\
\hline A. kingii MCP-3640 & Gravataí-RS & Macho & 21,4 & 4,8 \\
\hline A. kingii MCP-4061 & Canoas-RS & Macho & 23,9 & 6,2 \\
\hline A. kingii MCP-4735 & Porto Alegre-RS & Fêmea & 21,9 & 6,0 \\
\hline A. kingii MCP-5326 & Triunfo - RS & Fêmea & 19,4 & 4,7 \\
\hline A. kingii MCP-6638 & Porto Alegre-RS & Fêmea & 23,9 & 7,4 \\
\hline A. kingii MNRJ-7377 & RS & Macho & 19,1 & 3,3 \\
\hline A. anomala MPEG-5188 & Igarapé-Açu-PA & Macho & 25,1 & 13,6 \\
\hline A. anomala MPEG-6529 & Salinópolis-PA & Fêmea & 23,3 & 13,6 \\
\hline A. anomala MPEG-6565 & Bragança-PA & Macho & 27,2 & 21,3 \\
\hline A. anomala MPEG-10476 & Santa Rosa-PA & Macho & 29,1 & 23,5 \\
\hline A. anomala MNRJ-1772 & Belém-PA & Fêmea & 27,2 & 17,3 \\
\hline B. bedai IBDZBB-01 & Aquidauana-MS & Macho & $29,1^{*}$ & 14,4 \\
\hline B. bedai IBDZBB-02 & Aquidauana-MS & Fêmea & $29,4^{*}$ & 8,2 \\
\hline B. bedai IBDZBB-03 & Aquidauana-MS & Fêmea & 26,6 & 6,1 \\
\hline B. bedai IBDZBB-04 & Aquidauana-MS & Fêmea & 15,1 & 2,1 \\
\hline C. cuiabana IBDZCC-01 & Chapada dos Guimarães-MT & Macho & 24,8 & 3,9 \\
\hline C. cuiabana IBDZCC-02 & Chapada dos Guimarães-MT & Macho & 18,8 & 2,8 \\
\hline C. cuiabana IBDZCC-03 & Chapada dos Guimarães-MT & Fêmea & 15,8 & 1,6 \\
\hline C. cuiabana IBDZCC-04 & Chapada dos Guimarães-MT & Fêmea & 23,0 & 3,0 \\
\hline C. cuiabana IBDZCC-05 & Chapada dos Guimarães-MT & Macho & 25,0 & 4,1 \\
\hline L. microcephalum IBDZLM-04 & Corumbá-GO & Macho & 40,1 & 51,5 \\
\hline L. microcephalum IBDZLM-05 & Corumbá-GO & Macho & 38,6 & 50,2 \\
\hline L. microcephalum IBDZLM-06 & Corumbá-GO & Fêmea & 47,4 & 82,5 \\
\hline L. microcephalum IBDZLM-07 & Corumbá-GO & Macho & 34,0 & 36,9 \\
\hline L. microcephalum IBDZLM-08 & Corumbá-GO & Fêmea & 45,5 & 70,3 \\
\hline L. microcephalum IBDZLM-09 & Corumbá-GO & Fêmea & 42,2 & 55,5 \\
\hline L. microcephalum IBDZLM-10 & São Paulo-SP & Macho & 36,1 & 21,5 \\
\hline L. microcephalum IBDZLM-11 & São Paulo-SP & Fêmea & 42,5 & 61,0 \\
\hline
\end{tabular}


Tabela II. Amphisbaena vermicularis: dados relativos à posição inicial (pi) e posição final (pf) dos órgãos na cavidade pleuroperitoneal em relação aos anéis ventrais (número de anéis ventrais indicado em cada espécime). Cada espécime está identificado pela sigla e número de coleção. (MNRJ) Museu Nacional do Rio de Janeiro, clo-cloaca, (F) fêmea, (M) macho.

\begin{tabular}{|c|c|c|c|c|c|}
\hline Órgão pi-pf & MNRJ-7086 F & MNRJ-7090 F & MNRJ-7092 F & MNRJ-7087 M & MNRJ-7093 M \\
\hline Coração & $51-62$ & $52-61$ & $55-62$ & $57-66$ & $54-63$ \\
\hline Pulmão direito & $61-63$ & $61-63$ & $\mathrm{NI}$ & $65-66$ & $63-64$ \\
\hline Pulmão esquerdo & $62-123$ & $60-142$ & $62-120$ & $64-118$ & $62-122$ \\
\hline Fígado & $86-154$ & $85-165$ & $86-161$ & $86-157$ & $84-158$ \\
\hline Estômago & 165 & 172 & 173 & 165 & 155 \\
\hline Intestino delgado & $165-203$ & $173-206$ & $174-201$ & $166-210$ & $155-202$ \\
\hline Intestino grosso & 200 - clo & 204 - clo & 199 - clo & 204 - clo & 198 - clo \\
\hline Ovário direito & $174-190$ & $180-193$ & $181-191$ & - & - \\
\hline Ovário esquerdo & $178-192$ & $181-192$ & $183-191$ & - & - \\
\hline Testículo direito & - & - & - & $170-180$ & $169-180$ \\
\hline Testículo esquerdo & - & - & - & $172-181$ & $174-184$ \\
\hline Bexiga & $210-$ clo & 215 - clo & 219 - clo & 222 - clo & $214-$ clo \\
\hline Rim direito & 217 - clo & 219 - clo & 220 - clo & 224 - clo & 217 - clo \\
\hline Rim esquerdo & 215 - clo & 219 - clo & 221 - clo & 223 - clo & $217-$ clo \\
\hline Anéis ventrais & 236 & 235 & 236 & 242 & 237 \\
\hline
\end{tabular}

Tabela III. Anops kingi: dados relativos à posição inicial (pi) e posição final (pf) dos órgãos na cavidade pleuroperitoneal em relação aos anéis ventrais (número de anéis ventrais indicado em negrito). Espécimes identificados pela sigla e número de coleção. (MCP) Museu de Ciências e Tecnologia da PUCRS, (F) fêmea, (M) macho, clo-cloaca, (NI) não identificado.

\begin{tabular}{|c|c|c|c|c|c|c|}
\hline Órgão pi-pf & MCP-1240 F & MCP-4735 F & MCP-5326 F & MCP-6638 F & MCP-3640 M & MCP-4061 M \\
\hline Coração & $59-69$ & $60-71$ & $63-73$ & $58-70$ & $60-70$ & $62-73$ \\
\hline Pulmão direito & $\mathrm{NI}$ & $70-72$ & $\mathrm{NI}$ & $\mathrm{NI}$ & $\mathrm{NI}$ & $\mathrm{NI}$ \\
\hline Pulmão esquerdo & $67-135$ & $69-123$ & $71-151$ & $68-142$ & $68-140$ & $72-130$ \\
\hline Fígado & $87-160$ & $93-150$ & $94-171$ & $90-166$ & $85-162$ & $90-159$ \\
\hline Estômago & 163 & 163 & 180 & 170 & 169 & 171 \\
\hline Intestino delgado & $163-207$ & $163-208$ & $181-210$ & $170-206$ & $169-209$ & $171-206$ \\
\hline Intestino grosso & 203 - clo & 205 - clo & 205 - clo & 203 - clo & 206 - clo & 201 - clo \\
\hline Ovário direito & $166-174$ & $154-172$ & $173-191$ & $166-181$ & - & - \\
\hline Ovário esquerdo & $177-183$ & $169-179$ & $184-190$ & $175-186$ & - & - \\
\hline Testículo direito & - & - & - & - & $163-175$ & $164-174$ \\
\hline Testículo esquerdo & - & - & - & - & $173-185$ & $176-185$ \\
\hline Bexiga & $211-$ clo & 196 - clo & 212 - clo & 203 - clo & 199 - clo & 203 - clo \\
\hline Rim direito & 212 - clo & $204-$ clo & 216 - clo & 210 - clo & 209 - clo & 209 - clo \\
\hline Rim esquerdo & 212 - clo & 206 - clo & 215 - clo & 212 - clo & 209 - clo & 209 - clo \\
\hline Anéis ventrais & 230 & 224 & 232 & 228 & 230 & 229 \\
\hline
\end{tabular}

da cavidade corpórea, na linha mediana da mesma, e seu limite caudal não pode ser definido macroscopicamente (Fig 1). Embora uma dilatação no canal alimentar seja conspícua em alguns espécimes de C. cuiabana e de $B$. bedai, não é possível afirmar que a mesma determine os limites entre esôfago e estômago.

O esôfago une-se, do lado direito ao fígado através de ligamentos hepáticos-esofagiais e, do lado esquerdo ao pulmão, pelo ligamento pulmogástrico. 
Tabela IV. Aulura anomala: dados relativos à posição inicial (pi) e posição final (pf) dos órgãos na cavidade pleuroperitoneal em relação aos anéis ventrais (número de anéis ventrais indicado em negrito). Espécimes identificados pela sigla e número de coleção. (MNRJ) Museu Nacional do Rio de Janeiro, (MPEG) Museu Paraense Emilio Goeldi, (F) fêmea, (M) macho, clo-cloaca, (NI) não identificado.

\begin{tabular}{|c|c|c|c|c|}
\hline Órgão pi-pf & MNRJ $-1772 \mathrm{~F}$ & MPEG - $6529 \mathrm{~F}$ & MPEG -5188 M & MPEG - $6565 \mathrm{M}$ \\
\hline Coração & $48-56$ & $51-59$ & $51-58$ & $48-54$ \\
\hline Pulmão direito & $57-61$ & $60-65$ & $59-61$ & $54-57$ \\
\hline Pulmão esquerdo & $54-103$ & $59-109$ & $57-106$ & $53-109$ \\
\hline Fígado & $63-124$ & $71-138$ & $67-125$ & $60-129$ \\
\hline Estômago & 134 & 136 & 134 & 132 \\
\hline Intestino delgado & $134-162$ & $136-171$ & $134-169$ & $131-166$ \\
\hline Intestino grosso & $160-$ clo & 168 - clo & 167 - clo & 166 - clo \\
\hline Ovário direito & $134-144$ & $138-147$ & - & - \\
\hline Ovário esquerdo & $142-150$ & $152-154$ & - & - \\
\hline Testículo direito & - & - & $136-141$ & $138-141$ \\
\hline Testículo esquerdo & - & - & $146-151$ & $146-149$ \\
\hline Bexiga & 159 - clo & 177 - clo & 176 - clo & 156 - clo \\
\hline Rim dir. & 163 - clo & $172-$ clo & 167 - clo & 168 - clo \\
\hline Rim esq. & 163 - clo & 172 - clo & 167 - clo & 168 - clo \\
\hline Anéis ventrais & 182 & 186 & 183 & 185 \\
\hline
\end{tabular}

Tabela V. Bronia bedai: dados relativos à posição inicial (pi) e posição final (pf) dos órgãos na cavidade pleuroperitoneal em relação aos anéis ventrais (número de anéis ventrais indicado em negrito). Espécimes identificados pela sigla e número de coleção. (IBDZ) Instituto de Biociências, Departamento de Zoologia; (F) fêmea, (M) macho, clo-cloaca, (NI) não identificado.

\begin{tabular}{lccc}
\hline \multicolumn{1}{c}{ Órgão pi-pf } & IBDZBB-02 F & IBDZBB-03 F & IBDZBB-01 M \\
\hline Coração & $65-79$ & $68-79$ & $\mathrm{NI}-77$ \\
Pulmão direito & $\mathrm{NI}$ & $\mathrm{NI}$ & $76-144$ \\
Pulmão esquerdo & $77-142$ & $78-140$ & $99-183$ \\
Fígado & $98-196$ & $198-190$ & 196 \\
Estômago & 209 & $200-248$ & $196-251$ \\
Intestino delgado & $210-244$ & $242-$ clo & $246-$ clo \\
Intestino grosso & $240-$ clo & $210-221$ & - \\
Ovário direito & $217-248$ & $213-223$ & - \\
Ovário esquerdo & $223-247$ & - & $208-216$ \\
Testículo direito & - & - & $214-221$ \\
Testículo esquerdo & - & $258-$ clo & $259-$ clo \\
Bexiga & $261-$ clo & $259-$ clo & $266-$ clo \\
Rim direito & $262-$ clo & $259-$ clo & $268-$ clo \\
Rim esquerdo & $262-$ clo & 279 & 282 \\
Anéis ventrais & 280 & 2 & 2 \\
\hline
\end{tabular}

O estômago é um órgão cilíndrico, muscular e com diâmetro maior, em relação ao esôfago. Estende-se do terço médio até a porção inicial do terço caudal, da cavidade pleuroperitoneal, ocupando o antímero esquerdo da cavidade. Liga-se ao fígado pelo pequeno epíploo (ligamento gastro-hepático) de onde recebe vasto suporte sanguíneo. A região terminal do estômago é visivelmente mais estreita e contém um esfíncter muscular interno, o piloro, que delimita a passagem para o intestino delgado (Figs 5 e 6). 
Tabela VI. Cercolophia cuiabana: dados relativos à posição inicial (pi) e posição final (pf) dos órgãos na cavidade pleuroperitoneal em relação aos anéis ventrais (número de anéis ventrais indicado em negrito). Espécimes identificados pela sigla e número de coleção. (IBDZ) Instituto de Biociências, Departamento de Zoologia; (F) fêmea, (M) macho, clo-cloaca, (NI) não identificado.

\begin{tabular}{|c|c|c|c|c|c|}
\hline Órgão pi-pf & IBDZCC-03 F & IBDZCC-04 F & IBDZCC-05 M & IBDZCC-01 M & IBDZCC-02 M \\
\hline Coração & $74-85$ & $82-93$ & $78-87$ & $71-84$ & $74-88$ \\
\hline Pulmão direito & $\mathrm{NI}$ & $95-96$ & $\mathrm{NI}$ & $\mathrm{NI}$ & $\mathrm{NI}$ \\
\hline Pulmão esquerdo & $84-172$ & $92-173$ & $88-162$ & $81-160$ & $87-155$ \\
\hline Fígado & $110-194$ & $115-212$ & $110-197$ & $107-210$ & $107-210$ \\
\hline Estômago & 217 & 223 & 202 & 225 & 230 \\
\hline Intestino delgado & $217-245$ & $223-258$ & $201-255$ & $225-263$ & $231-270$ \\
\hline Intestino grosso & 242 - clo & 255 - clo & 251 - clo & 258 - clo & 266 - clo \\
\hline Ovário direito & $\mathrm{NI}$ & $234-245$ & - & - & - \\
\hline Ovário esquerdo & $\mathrm{NI}$ & $241-248$ & - & - & - \\
\hline Testículo direito & - & - & $221-228$ & $242-246$ & $234-242$ \\
\hline Testículo esquerdo & - & - & $227-232$ & $245-250$ & $242-249$ \\
\hline Bexiga & 252 - clo & 275 - clo & $270-$ clo & 277 - clo & 282 - clo \\
\hline Rim direito & 261 - clo & 279 - clo & 262 - clo & 278 - clo & 281 - clo \\
\hline Rim esquerdo & 262 - clo & $280-$ clo & 264 - clo & 278 - clo & 282 - clo \\
\hline Anéis ventrais & 288 & 303 & 289 & 300 & 304 \\
\hline
\end{tabular}

Tabela VII. Leposternon microcephalum: dados relativos à posição inicial (pi) e posição final (pf) dos órgãos na cavidade pleuroperitoneal em relação aos anéis ventrais (número de anéis ventrais indicado em negrito). Espécimes identificados pela sigla e número de coleção. (IBDZ) Instituto de Biociências, Departamento de Zoologia; (F) fêmea, (M) macho, clo-cloaca, (NM) não mensurado.

\begin{tabular}{|c|c|c|c|c|c|c|c|}
\hline Órgão pi-pf & IBDZLM-06 F & IBDZLM-08 F & IBDZLM-09 F & IBDZLM-11 F & IBDZLM-04 M & IBDZLM-07 M & IBDZLM-10 M \\
\hline Coração & $50-61$ & $46-55$ & $53-61$ & $48-58$ & $48-57$ & $53-63$ & $51-60$ \\
\hline Pulmão direito & $58-63$ & $53-57$ & $61-64$ & $58-66$ & $56-61$ & $61-70$ & $61-67$ \\
\hline Pulmão esquerdo & $57-117$ & $53-119$ & $60-125$ & $57-122$ & $57-120$ & $61-128$ & $60-118$ \\
\hline Fígado & $76-140$ & $74-140$ & $82-141$ & $80-139$ & $78-135$ & $85-147$ & $77-136$ \\
\hline Estômago & 139 & 140 & 141 & 142 & 136 & 153 & 140 \\
\hline Intestino delgado & $140-167$ & $139-187$ & $142-175$ & $143-179$ & $137-167$ & $153-175$ & $141-175$ \\
\hline Intestino grosso & $162-$ clo & 185 - clo & $173-$ clo & 177 - clo & 165 - clo & $174-$ clo & 172 - clo \\
\hline Ovário direito & $143-163$ & NM & $146-157$ & $150-166$ & - & - & - \\
\hline Ovário esquerdo & $150-161$ & NM & $150-159$ & $151-164$ & - & - & - \\
\hline Testículo direito & - & - & - & - & $142-154$ & $151-158$ & $150-158$ \\
\hline Testículo esquerdo & - & - & - & - & $146-154$ & $157-162$ & $158-161$ \\
\hline Bexiga & 171 - clo & 186 - clo & 182 - clo & 172 - clo & $180-$ clo & 174 - clo & $170-$ clo \\
\hline Rim direito & 193 - clo & 191 - clo & 190 - clo & 180 - clo & 183 - clo & 191 - clo & 186 - clo \\
\hline Rim esquerdo & 193 - clo & 191 - clo & 187 - clo & 180 - clo & 183 - clo & $191-$ clo & 186 - clo \\
\hline Anéis ventrais & 213 & 209 & 211 & 203 & 204 & 211 & 207 \\
\hline
\end{tabular}

A porção cranial do intestino delgado, que se segue ao piloro, pode apresentar-se como uma câmara mais ou menos dilatada e proeminente (Figs 5 e 6). Em A. vermicularis e L. microcephalum esta região é mais dilatada e conspícua do que nas demais espécies. Em A. anomala, C. cuiabana e B. bedai nota-se uma porção mais dilatada pós-piloro, em alguns espécimes, mas não em outros. Em A. kingii esta característica não foi observada nos espécimes examinados. 

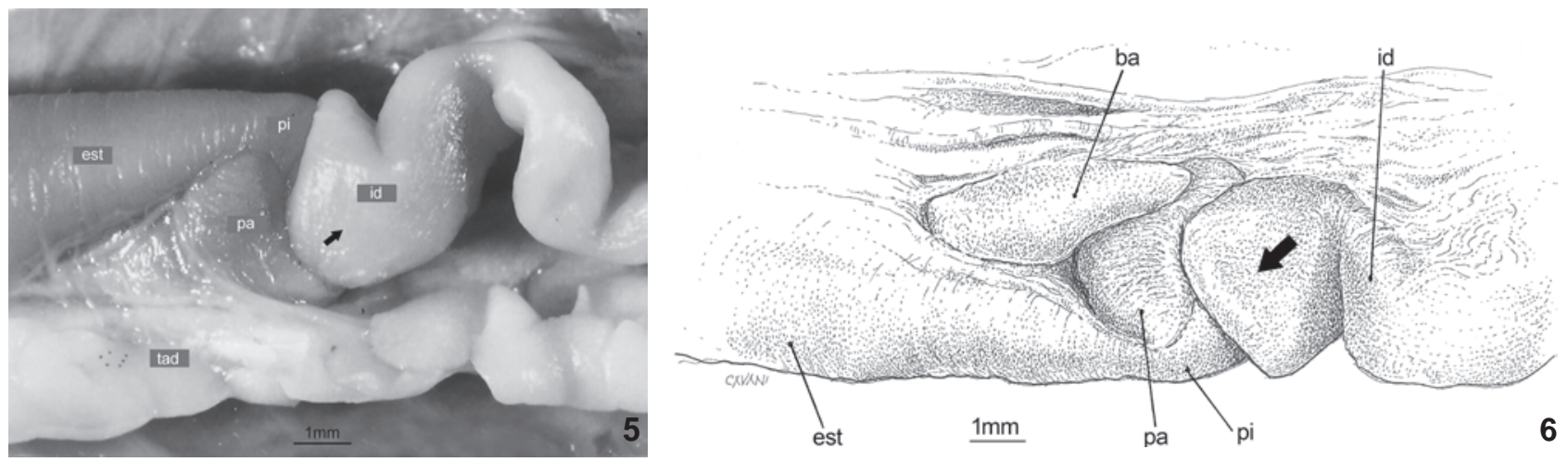

Figuras 5-6. Amphisbaena vermicularis: morfologia externa do canal alimentar. Região do estômago e intestino delgado em vista (5) ventral e (6) dorsal. (ba) Baço, (est) estômago, (id) intestino delgado, (pa) pâncreas, (pi) piloro, (tad) tecido adiposo. A seta indica a região cranial do intestino delgado, mais alargada. Barra de escala $=1 \mathrm{~mm}$.

Tabela VIII. Dados relativos à média das proporções do pulmão direito em relação ao pulmão esquerdo, com base nos valores de comprimento obtidos em pelo menos um indivíduo de cada espécie, no qual o pulmão direito foi visualizado.

\begin{tabular}{lc}
\hline \multicolumn{1}{c}{ Espécie } & Pulmão direito/esquerdo (\%) \\
\hline Amphisbaena vermicularis & - \\
Anops kingii & 4,6 \\
Aulura anomala & 7,5 \\
Bronia bedai & - \\
Cercolophia cuiabana & - \\
Leposternon microcephalum & 9,2 \\
\hline
\end{tabular}

Nos espécimes A. anomala MPEG-6529 (Fig. 7) e A. vermicularis MNRJ-7086 foram observadas intussuscepções do intestino delgado, caracterizadas pela invaginação de uma alça intestinal em outra.

O limite entre o intestino delgado e o intestino grosso é nítido em todos os espécimes examinados, devido à presença do ceco, que se projeta em sentido cranial e dorsal ocupando o antímero esquerdo da cavidade pleuroperitoneal (Fig. 8). Variações intra e interespecíficas com relação às dimensões do ceco foram observadas, embora as mesmas não tenham sido mensuradas. O intestino grosso é um tubo reto e cilíndrico, que se estende pela linha mediana da cavidade pleuroperitoneal até a cloaca, onde se abre através do ânus.

Os intestinos estão alojados no terço caudal da cavidade pleuroperitoneal e prendem-se à mesma através do mesentério.

A posição do estômago e do intestino delgado varia consideravelmente na cavidade pleuroperitoneal, entre os espécimes examinados. Somente em $A$. anomala a variação é menor (Tabs II-VII).

O pâncreas possui coloração amarelo-leitosa, nos espécimes recém-sacrificados, e situa-se do lado direito da cavidade pleuroperitoneal, onde se aloja entre o piloro e o intestino delgado. Sua superfície ventral é triangular e alonga-se dorsalmente envolvendo de forma parcial a face dorsal do piloro e a porção cranial dorsal do intestino delgado (Figs 5 e 6).

O baço possui forma oval e coloração marrom-avermelhada, nos espécimes recém-sacrificados. Localiza-se crânio-dorsalmente ao pâncreas, limitando-se com a face lateral deste, no antímero direito da cavidade pleuroperitoneal (Fig. 6). Encontra-se fixo à região do piloro pelo grande epíploo.

O fígado é um órgão de coloração marrom-avermelhada. Está localizado ventralmente ao esôfago e estômago e deslocado para o lado direito da cavidade pleuroperitoneal, ocupando o terço médio da mesma. É o órgão de maior extensão em anéis (e maior comprimento) na cavidade do corpo (Tabs II-VII).

Sua porção cranial, delgada e afilada, é atravessada longitudinalmente pela veia pós-cava, enquanto a porção caudal apresenta-se fendida em dois lobos desiguais (Fig. 9). O lobo hepático direito é delgado enquanto o esquerdo é largo e arredondado. Um ou outro lobo pode apresentar-se secundariamente fendido.

Em todos os espécimes examinados, o lobo direito do fígado é maior do que o esquerdo em extensão. As maiores diferenças foram observadas nos espécimes de $B$. bedai e $C$. cuiabana, nos quais o lobo hepático direito estendia-se por mais de 20 anéis além do esquerdo. Os espécimes de $B$. bedai apresentavam o fígado muito recortado nas laterais, dando origem a sub-lobos.

$\mathrm{O}$ fígado encontra-se ancorado à parede ventral do corpo pelo ligamento falciforme e dorsalmente ao estômago pelo pequeno epíploo. Sua posição na cavidade pleuroperitoneal apresentou pouca variação intraespecífica, a não ser pelas diferenças individuais relatadas entre os comprimentos dos lobos direito e esquerdo.

A vesícula biliar é ovalada e possui coloração verde-escura. Localiza-se em uma fenda entre os dois lobos hepáticos (Fig. 9). 

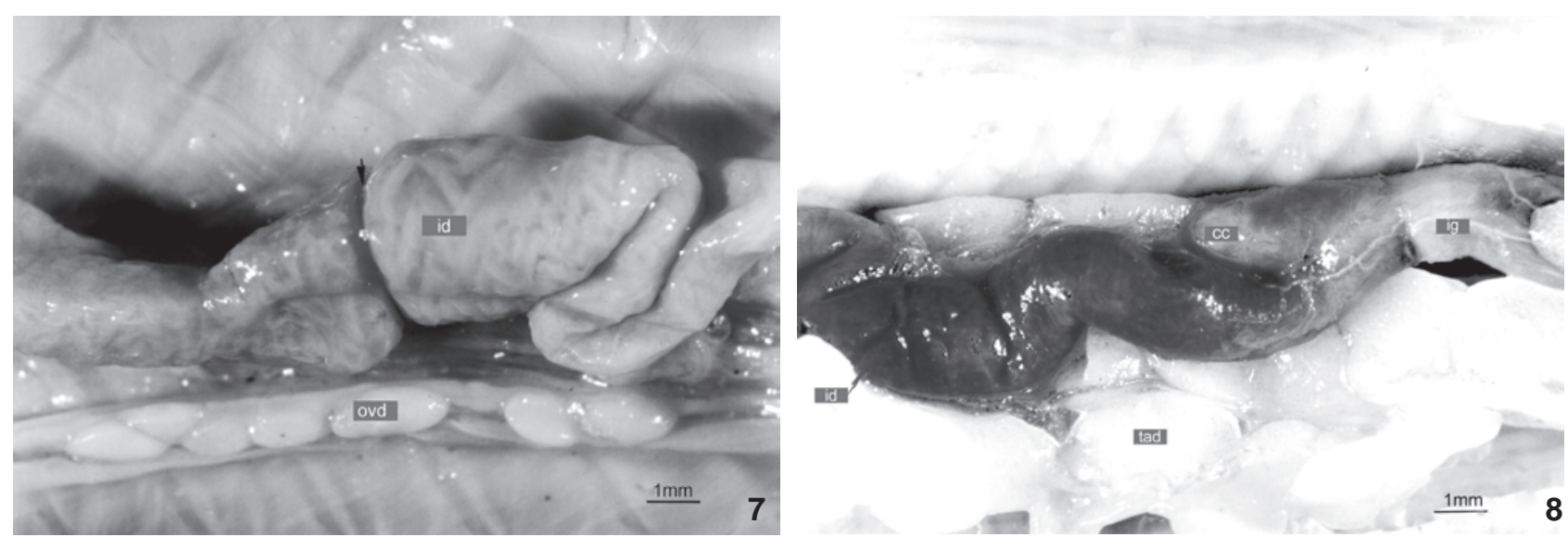

Figuras 7-8. Morfologia externa do canal alimentar. (7) Aulura anomala: região do intestino delgado, em vista ventral, mostrando intussuscepção intestinal (indicada pela seta); (8) Cercolophia cuiabana: região do intestino delgado e intestino grosso , em vista ventral, mostrando ceco conspícuo. (cc) Ceco, (id) intestino delgado, (ig) intestino grosso, (ovd) ovário direito com folículos, (tad) tecido adiposo. Barra de escala $=1 \mathrm{~mm}$.

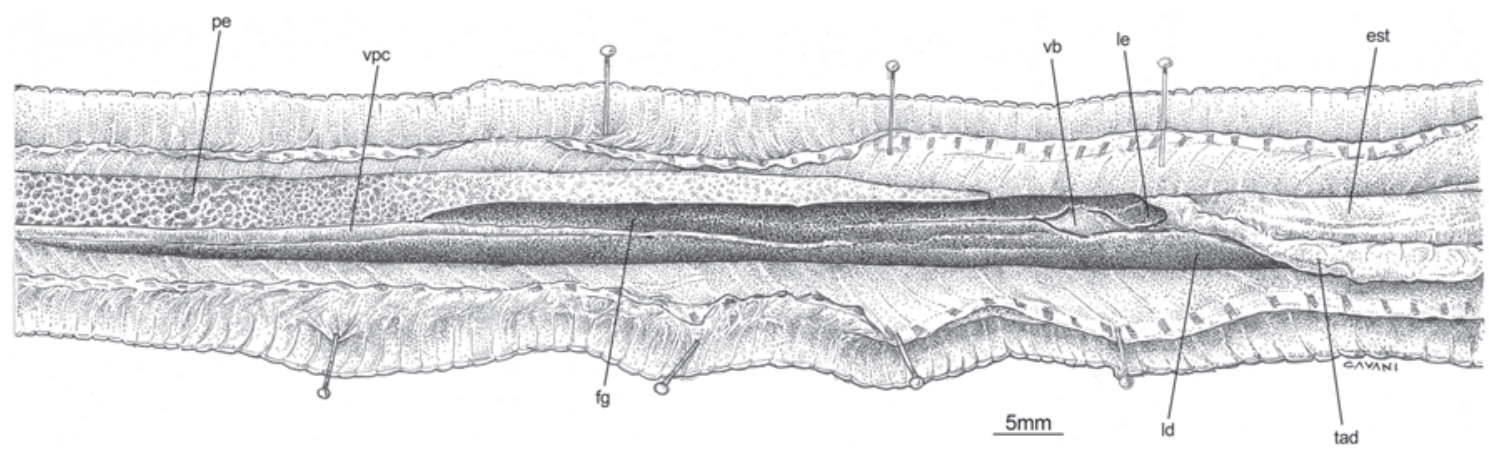

Figura 9. Amphisbaena vermicularis: morfologia externa do fígado, em vista ventral. (est) Estômago, (fg) fígado, (ld) lobo hepático direito, (le) lobo hepático esquerdo, (pe) pulmão esquerdo, (tad) tecido adiposo, (vb) vesícula biliar. Barra de escala = 5 mm.

Ovários e ovidutos localizam-se no terço caudal da cavidade pleuroperitoneal em posição látero-dorsal aos intestinos. Cada ovário é um tubo longo, delgado, transparente, no interior do qual é possível verificar a presença de folículos que se dispõem, em geral, linearmente ao longo do eixo crânio-caudal do órgão (Figs 7 e 10). É a presença dos folículos que facilita o estabelecimento dos limites de cada ovário, pois em exemplares juvenis, é praticamente impossível delimitá-los. Em todos os espécimes examinados, o ovário direito localiza-se cranialmente ao esquerdo e é também maior (Tabs II-VII).

Os ovidutos são tubos bastante alongados que se encontram lateralmente à face externa dos ovários e, na região caudal da cavidade pleuroperitoneal seguem acolados à margem lateral de cada rim até a cloaca, onde desembocam através do orifício genital. O oviduto direito é também mais extenso e mais cranial que o esquerdo. Tanto os ovários como os ovidutos são sustentados, respectivamente, pelo mesovário e mesotubário, na cavi- dade pleuroperitoneal (Fig. 10).

Nos espécimes adultos, os ovários são mais evidentes por conterem folículos de maiores dimensões em seu interior e os ovidutos são mais convolutos apresentando o funil muito conspícuo, facilitando o estabelecimento de seus limites (Fig. 11).

Num espécime de L. microcephalum (IBDZLM-08) os ovários continham quatro folículos grandes: dois no ovário direito medindo 31,2 mm de comprimento por 10,5 mm de largura e $17,3 / 5,3 \mathrm{~mm}$, respectivamente e dois no ovário esquerdo medindo $13,5 / 4,5 \mathrm{~mm}$ e $25,8 / 10,9 \mathrm{~mm}$, respectivamente. Os folículos eram de coloração amarelo-escura, evidenciando a presença de vitelo em seu interior e sugerindo atividade reprodutiva (Fig. 11).

Os testículos apresentam coloração amarelo-leitosa e localizam-se no terço caudal da cavidade pleuroperitoneal, láterodorsalmente aos intestinos e são sustentados pelo mesórquio. A forma dos mesmos varia entre as espécies consideradas podendo ser mais ou menos alongados, ovais ou reniformes. Em 


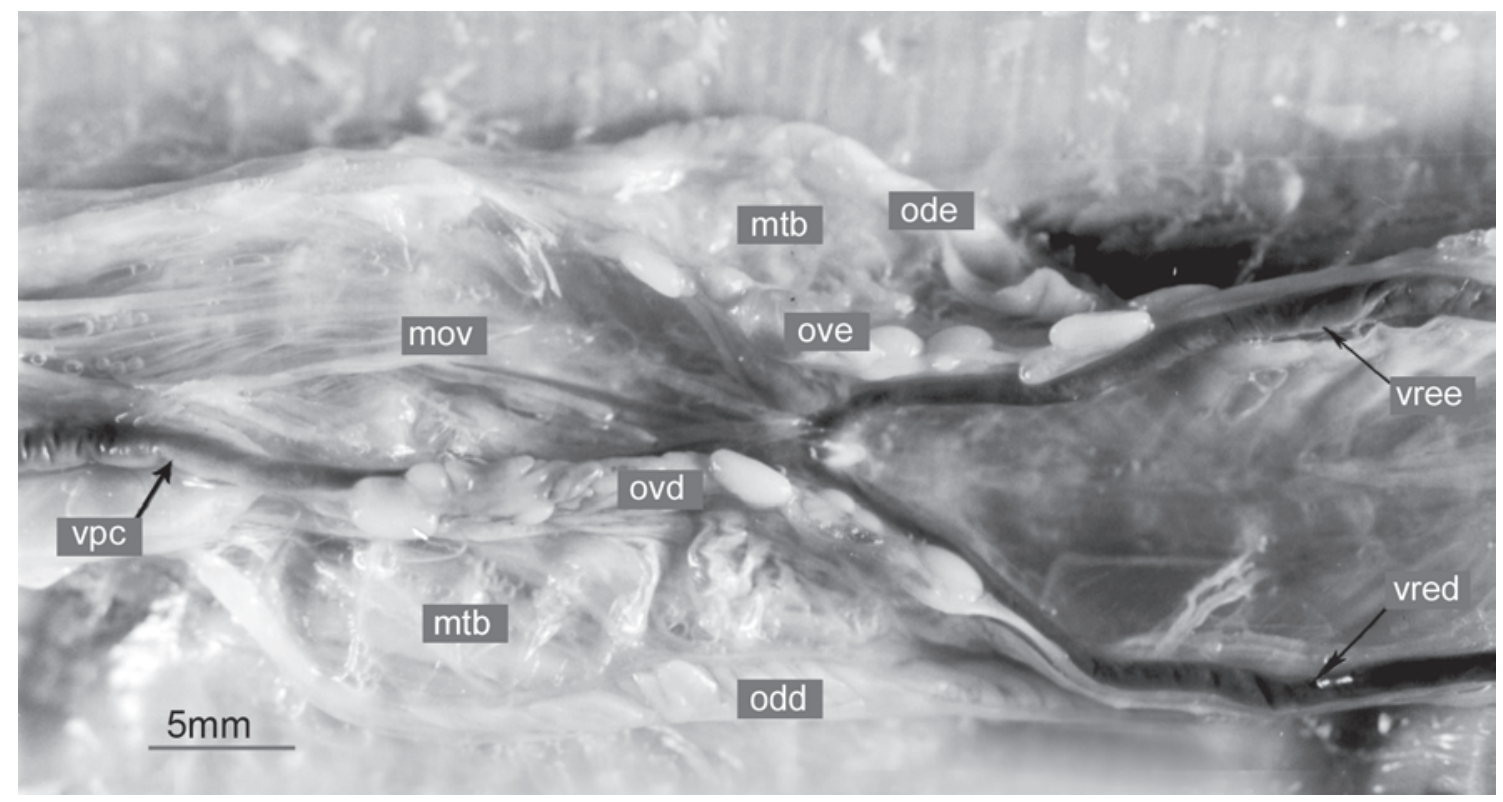

Figura 10. Leposternon microcephalum: morfologia externa dos ovários e ovidutos, em vista ventral. (mov) Mesovário, (mtb) mesotubário, (odd) oviduto direito, (ode) oviduto esquerdo, (ovd) ovário direito, (ove) ovário esquerdo, (vpc) veia pós-cava, (vred) veia renal eferente direita, (vree) veia renal eferente esquerda. Barra de escala $=5 \mathrm{~mm}$.

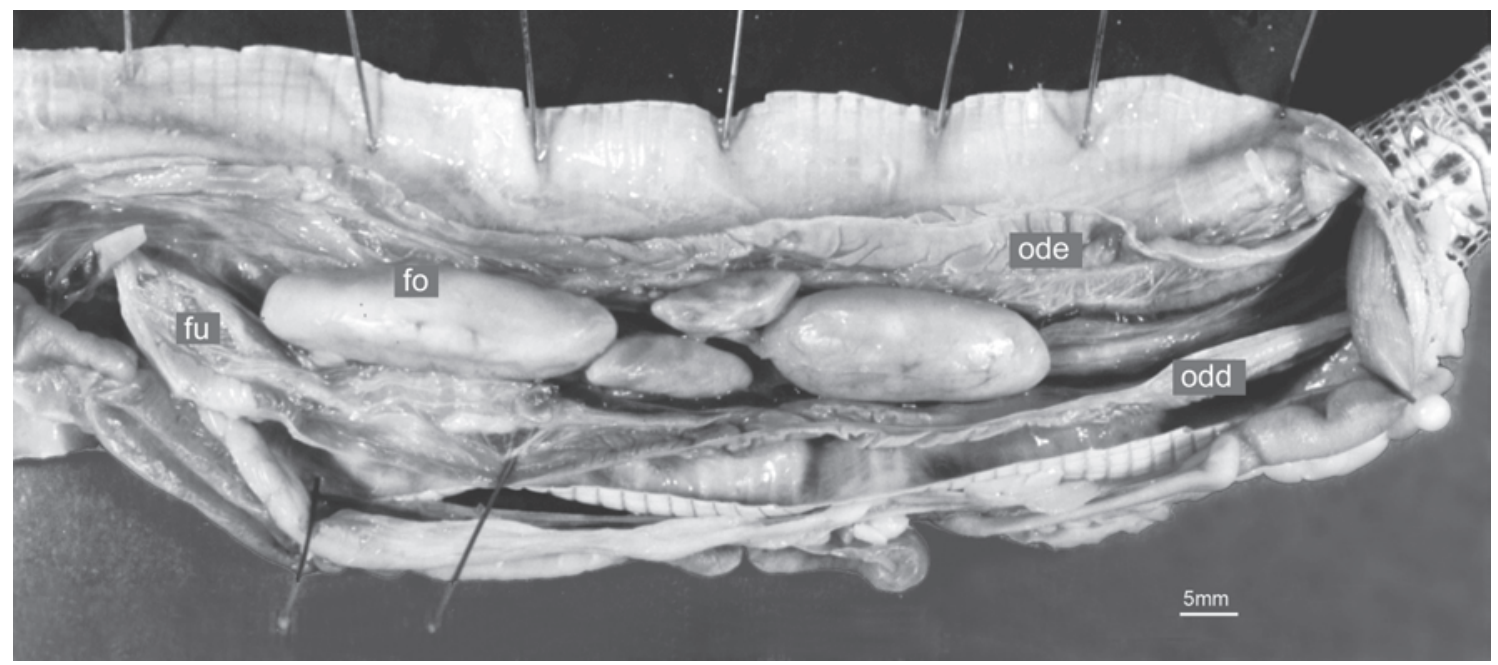

Figura 11. Leposternon microcephalum: morfologia externa do aparelho genital de uma fêmea, com folículos maduros e ovidutos convolutos, em vista ventral. (fo) Folículo, (fu) funil do oviduto, (odd) oviduto direito, (ode) oviduto esquerdo. Barra de escala = $5 \mathrm{~mm}$.

B. bedai, estes órgãos são acentuadamente reniformes (Fig. 12), enquanto em A. kingii (Fig. 13), A. vermicularis, C. cuiabana e $L$. microcephalum são mais longos do que largos e em A. anomala, são ovais (Fig. 14). Nas seis espécies, os testículos apresentamse ligeiramente achatados dorso-ventralmente.

O testículo direito localiza-se em posição mais cranial que o esquerdo, em todos os espécimes examinados (Figs 12-14)
(Tabs II-VII). É também maior que o esquerdo, exceto nos exemplares de A. kingii MCP-3640 e MNRJ-7377, cujos testículos esquerdos mostram-se maiores e, nos espécimes $A$. anomala MEPG-5188 e C. cuiabana IBDZCC-01, nos quais ambos os testículos têm o mesmo tamanho.

O ducto deferente emerge da face interna de cada testículo e dirige-se em sentido caudal, passando pela face lateral do 


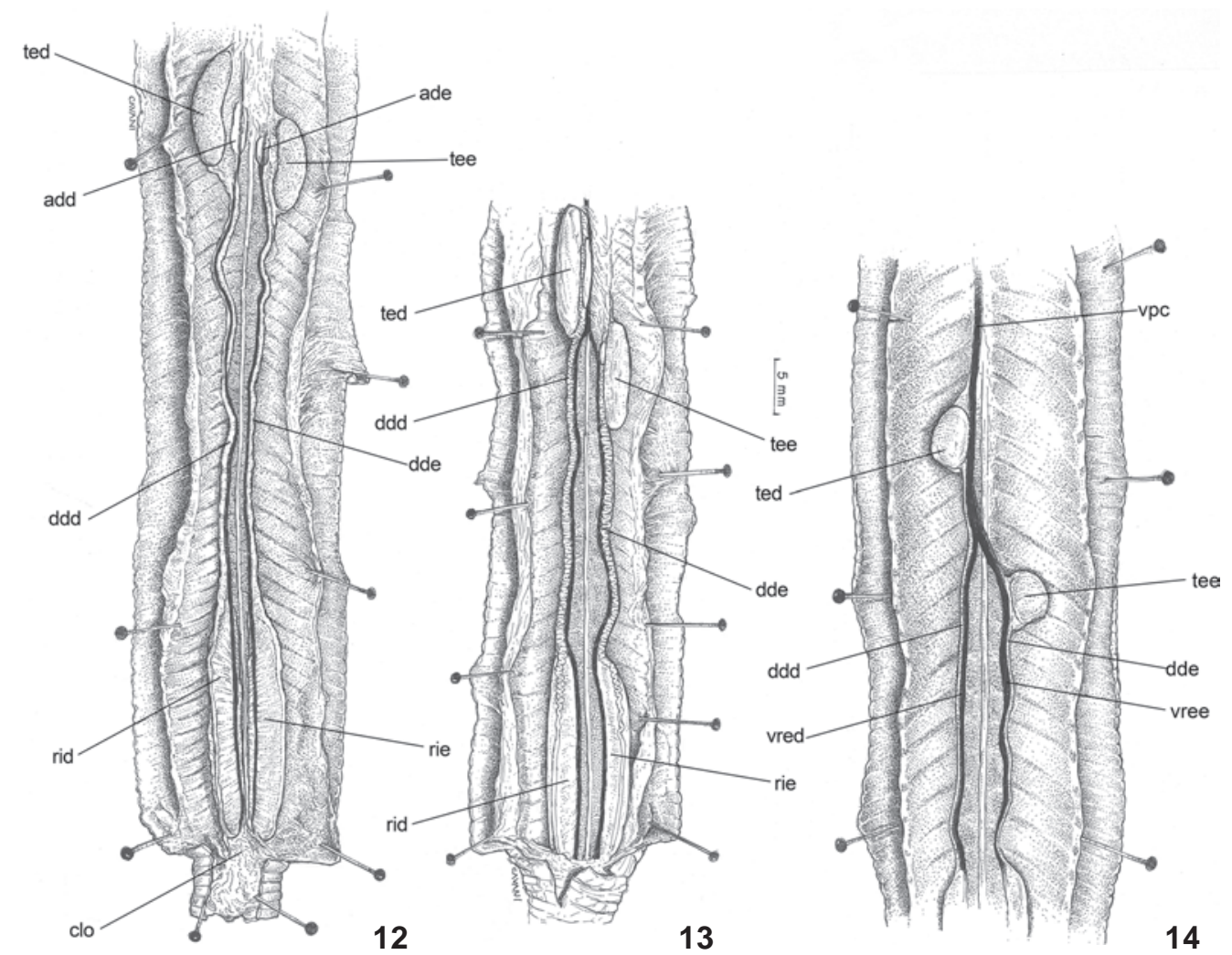

Figuras 12-14. Morfologia externa do aparelho urogenital, em vista ventral, mostrando testículos de formatos variados: (12) B. bedai, (13) A. kingii, (14) A. anomala. (add) Adrenal direita, (ade) adrenal esquerda, (ddd) ducto deferente direito, (dde) ducto deferente esquerdo, (rid) rim direito, (rie) rim esquerdo, (ted) testículo direito, (tee) testículo esquerdo, (vpc) veia pós-cava, (vred) veia renal eferente direita, (vree) veia renal eferente esquerda. Barra de escala $=5 \mathrm{~mm}$.

rim, desembocando na cloaca através dos orifícios urogenitais. Em alguns espécimes, os ductos deferentes apresentam-se espessados e convolutos (Fig. 13).

As adrenais são glândulas alongadas, ligeiramente lobuladas, de coloração amarelo-escura. Localizam-se medialmente às gônadas, na porção mesovariana ou mesorquiana do mesentério urogenital. A glândula adrenal direita está localizada mais cranialmente que a esquerda, acompanhando o deslocamento unilateral das gônadas e é também maior que a esquerda (Fig. 12).

Os rins são órgãos retroperitoneais que se localizam dorso-lateralmente ao intestino grosso, na altura da porção caudal da cavidade corpórea. São órgãos alongados de coloração rósea. Embora estejam posicionados simetricamente um em relação ao outro, um rim pode ter maior comprimento que o outro e, por esta razão, localizar-se mais cranialmente (Figs 12, 13 e 15). Os ureteres emergem da face medial de cada rim e desembocam no urodeu em uma posição ventral ao ânus.

Nos espécimes de A. anomala considerados para sintopia (Tab. IV) os rins são do mesmo comprimento e estão simetricamente posicionados. No entanto, o espécime MEPG-10476 (não mostrado na tabela) possui o rim esquerdo maior que o direito.

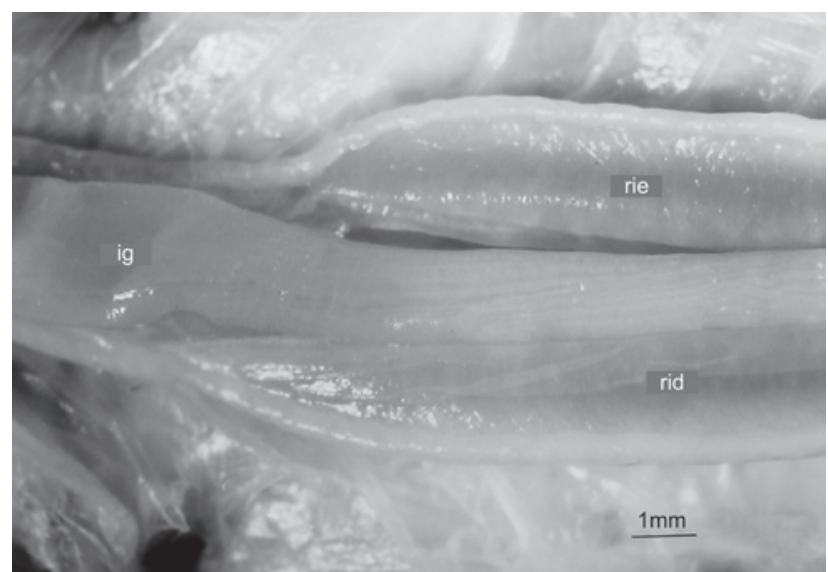

Figura 15. Cercolophia cuiabana: morfologia externa dos rins, em vista ventral. (ig) Intestino grosso, (rid) rim direito maior, (rie) rim esquerdo. Barra de escala $=1 \mathrm{~mm}$.

Em A. vermicularis, cinco espécimes, dos nove examinados, possuem rins de mesmo comprimento; dois possuem o esquer- 

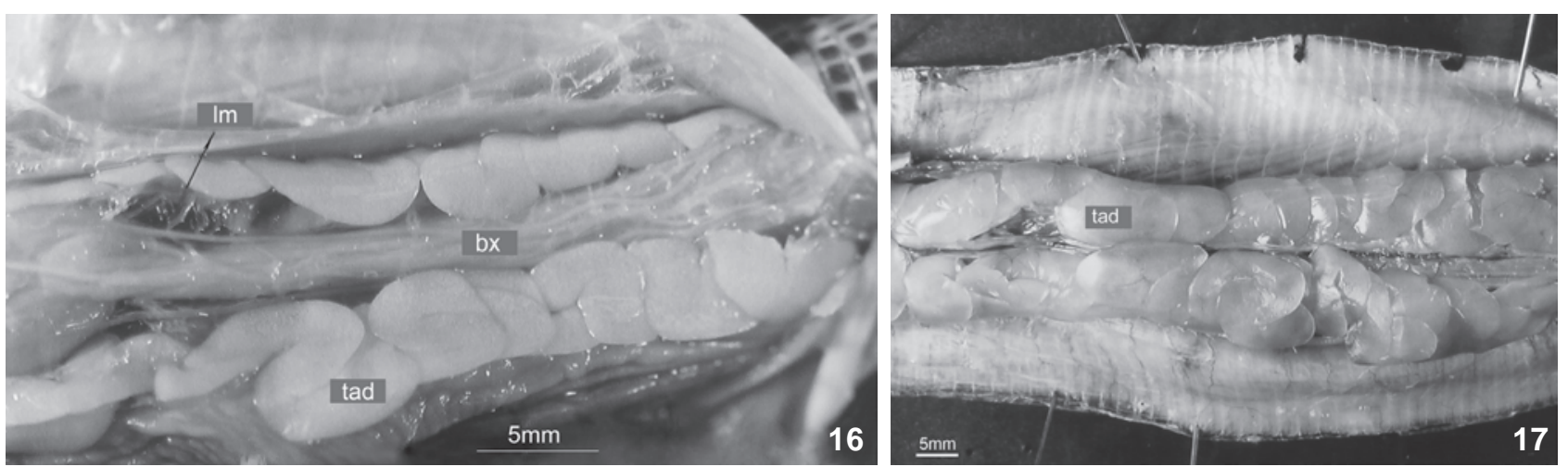

Figuras 16-17. Leposternon microcephalum. (16) Morfologia externa da bexiga urinária entre as massas de tecido adiposo, em vista ventral; (17) morfologia externa do terço caudal da cavidade pleuroperitoneal, em vista ventral, mostrando a distribuição das massas de tecido adiposo recobrindo as vísceras. (bx) Bexiga urinária, ( $\mathrm{Im}$ ) lâmina mesentérica, (tad) tecido adiposo. Barra de escala = 5 mm.

do mais longo que o direito e, nos outros dois ocorre o inverso (na tabela II estão representados somente os cinco espécimes utilizados para sintopia). Em A. kingii, quatro espécimes possuem os rins de mesmo comprimento, em dois espécimes o rim direito é mais longo e, um exemplar possui o rim esquerdo maior que o direito (Tab. III - apenas seis dos sete espécimes examinados). Em B. bedai, dois espécimes possuem rins de igual comprimento e dois apresentam o rim direito mais longo que o esquerdo (na tabela V são mostrados os dados relativos apenas aos três espécimes utilizados para sintopia). Em C. cuiabana, o rim direito é mais longo que o esquerdo exceto no espécime IBDZCC-01, cujos rins possuem o mesmo comprimento (Tab. VI - todos os espécimes examinados constam na tabela). Em $L$. microcephalum, dois espécimes possuem o rim esquerdo mais longo que o direito, nos demais, os rins são do mesmo tamanho (na tabela VII são mostrados os dados relativos a sete espécimes dos oito examinados).

A bexiga urinária é um órgão ímpar, saculiforme, alongado e semi-transparente, que se abre na cloaca, ventralmente ao intestino grosso. Está localizada na linha mediana do corpo, na porção caudal da cavidade pleuroperitoneal, entre as massas de tecido adiposo e dorsal a estas, às quais se une através da lâmina mesentérica (Fig. 16). A posição da bexiga urinária varia consideravelmente intra e interespecificamente (Tabs II-VII).

Tecido adiposo constituído de pequenas massas lobuladas, unidas entre si pela lâmina peritoneal, recobre ventralmente o terço caudal da cavidade pleuroperitoneal, da região caudal do fígado até a cloaca (Figs 16 e 17). O tecido adiposo está unido ao canal alimentar apenas na região do piloro, através do mesentério (Fig. 5). Massas deste tecido estão presentes também na região próxima ao coração, recobrindo ventralmente parte dos principais vasos que ali se encontram.

A coloração e a quantidade do tecido adiposo apresentam variações entre os espécimes examinados. Foram observadas massas de tecido adiposo de coloração branco-opaca, branco-brilhante, amarelo-clara, amarelo-escura ou ligeiramente rosada. As diferenças com relação à quantidade deste tecido não foram mensuradas.

\section{DISCUSSÃO}

Devido ao hábito fossório dos anfisbênios, existe uma real dificuldade na obtenção de exemplares para estudo. Por esta razão, o tamanho da amostra neste estudo inviabilizou a realização de análises estatísticas que permitissem avaliar diferenças significativas entre os resultados obtidos para a posição das vísceras na cavidade pleuroperitoneal, intra e interespecificamente. No entanto, várias considerações puderam ser tecidas com relação aos órgãos examinados, entre as espécies estudadas.

De acordo com Gans (1975), a perda ou redução de membros está associada à elongação do corpo e a redução do diâmetro do mesmo em relação ao comprimento total (focinho-cauda). A elongação do corpo, por sua vez, leva à elongação das vísceras e ao deslocamento dos órgãos pareados, fazendo com que um esteja em posição mais cranial que o outro. Em alguns casos, pode provocar também a redução unilateral de um órgão par, como é observado em relação aos pulmões de várias espécies.

A redução do pulmão direito, e não do esquerdo como acontece na maioria das serpentes e lagartos alongados é uma característica peculiar dos Amphisbaenia (Butler 1895). No entanto, o grau de redução do pulmão direito em anfisbênios varia entre as espécies, conforme observado neste e nos estudos realizados por Crook \& PARsons (1980), que examinaram 16 espécies pertencentes às quatro famílias até então reconhecidas.

O pulmão direito é conspícuo em todos os espécimes de A. anomala e L. microcephalum, que apresentam os menores graus de redução deste órgão quando comparado às demais espécies estudadas. Este fato, aliado ao tamanho maior destas espécies, facilita a identificação das estruturas internas. Nas espécies em que o pulmão direito foi observado em alguns indivíduos, mas não em outros é provável que o reduzido tamanho das espécies, aliado à má preservação das vísceras tenha contribuído para 
estes resultados. Em B. bedai, embora o pulmão direito não tenha sido visualizado em nenhum dos espécimes examinados, não é possível afirmar que este órgão esteja ausente na espécie, devido à baixa amostragem.

Nos anfisbênios da família Trogonophidae e numa espécie estudada de Bipedidae, Bipes biporus (Cope, 1894), o pulmão direito é relativamente grande, cerca de $1 / 5$ a 2/3 do comprimento do esquerdo (Gans 1960, Crook \& Parsons 1980). O pulmão direito não foi observado nos Amphisbaenidae Amphisbaena darwinii Duméril \& Bibron, 1839; Amphisbaena manni Barbour, 1914; Anops kingii; Chirindia rondoense (Loveridge, 1941); Cynisca leucura (Dumeril \& Bibron, 1839); Zygaspis quadrifrons (Peters, 1862), nem em Blanus cinereus (Vandelli, 1797) (Blanidae) e Rhineura floridana (Rhineuridae) examinados por CRook \& PARsons (1980).

Segundo Gans (1978), os Amphisbaenia mostram uma redução gradual no pulmão direito em paralelo ao aumento nas modificações associadas com a escavação. No entanto, esta tendência parece ter ocorrido somente em Trogonophidae, na qual o gênero mais primitivo, Trogonophis apresenta o menor grau de redução do pulmão direito em relação aos gêneros Agamodon e Diplometopon considerados mais especializados para a escavação (GANs 1960). Nos Amphisbaenidae estudados observou-se o contrário, ou seja, L. microcephalum e A. anomala, espécies consideradas mais especializadas para a escavação por apresentarem, entre outras características, a cabeça em formade-pá (GANs 1968) possuem o pulmão direito proporcionalmente maior do que nas demais espécies. As formas menos especializadas para escavação, com cabeça arredondada (GANs 1968), como A. vermicularis, B. bedai e C. cuiabana, apresentam o pulmão direito muito reduzido ou ausente. Como o pulmão direito foi identificado em apenas um dos exemplares de $A$. kingii - anfisbenídeo com cabeça em forma de quilha - examinados neste estudo e, também não foi observado por CROоK \& PARsons (1980), nos indivíduos desta espécie, não é possível fazer associações entre a característica especializada da cabeça com o grau de redução do referido órgão.

Espécies do gênero africano Monopeltis Smith, 1848 (Amphisbaenidae) com cabeça em forma-de-pá, ocorrem em solos profundos em zonas onde são simpátricas com $Z$. quadrifrons habitante de superfície, com cabeça arredondada (Gans 1974). De acordo com os estudos de Crook \& Parsons (1980), em Z. quadrifrons, o pulmão direito está ausente e em Monopeltis capensis Smith, 1848 o pulmão direito equivale a $8 \%$ do esquerdo, proporção semelhante àquelas encontradas em A. anomala e L. microcephalum, neste estudo.

Anops kingii, L. microcephalum e A. anomala, formas mais especializadas para a escavação, possuem o pulmão esquerdo proporcionalmente maior e um pulmão direito menos reduzido (observado em apenas um espécime de $A$. kingii) que os espécimes de $A$. vermicularis, $B$. bedai e $C$. cuiabana, formas consideradas menos especializadas para escavação. É provável que a disponibilidade de um volume maior de tecido pulmonar, por- tanto, uma área maior para trocas gasosas e reserva de ar possa estar relacionada à menor disponibilidade de oxigênio encontrada em solos mais profundos e compactados, onde os escavadores mais especializados vivem.

A gônada direita está posicionada cranialmente em relação à esquerda, em todos os espécimes examinados neste estudo. Segundo a literatura, o testículo e ovário direitos, acompanhados pelos seus respectivos ductos e das glândulas adrenais, obedecem este mesmo padrão anatômico nas espécies de anfisbênios estudadas (Crook \& Parsons 1980, Navega-GonçalVEs \& SOUZa 2001) e nas serpentes (O'Donoghue 1912, Bradgon 1953, W. Fox 1965, H. Fox 1977, Lécuru-Renous \& Platel 1970, Gomes et al. 1989, Gomes \& Puorto 1993).

O ovário direito é também maior que o esquerdo nas seis espécies estudadas. Em $A$. mertensi todas as fêmeas examinadas apresentavam o ovário direito maior que o esquerdo (NAvEGAGonçalves \& Souza 2001). Da mesma forma, Crook \& PARsons (1980) observaram que o ovário direito, da maioria dos anfisbenídeos por eles examinados, é consideravelmente maior que o esquerdo, com exceção de um espécime de $C$. rondoense e de $M$. capensis, nos quais ambos ovários apresentavam o mesmo tamanho. Também entre os trogonofídeos, em um espécime de Agamodon anguliceps Peters, 1882 e um espécime de Diplometopon zarudnyi Nikolski, 1907, os ovários direito e esquerdo apresentavam o mesmo tamanho. No entanto, em $R$. floridana e em Bipes canaliculatus Bonnaterre, 1789, os respectivos ovários esquerdos mostraram-se ligeiramente maiores.

Com relação aos testículos, observou-se que dois espécimes de $A$. kingii possuem o testículo esquerdo maior que o direito e um espécime de $A$. anomala e de $C$. cuiabana, apresentam os testículos de mesmo tamanho. Nos demais espécimes, o testículo direito é maior que o esquerdo. Em $A$. mertensi, apenas nos indivíduos adultos o testículo direito mostrou-se maior que o esquerdo, nos juvenis os testículos tinham o mesmo tamanho (Navega-Gonçalves \& Souza 2001). De acordo com as observações de Crook \& PArsons (1980), entre os anfisbenídeos examinados, todos os quatro machos de C. leucura possuíam o testículo direito notavelmente maior que o esquerdo; em um espécime de $A$. alba o testículo esquerdo era maior e, em outro ambos eram do mesmo tamanho. No trogonofídeo A. anguliceps, dos quatro machos examinados, dois possuíam o testículo direito maior, um apresentava o esquerdo ligeiramente maior que o direito, e no outro, os testículos tinham iguais tamanhos. Finalmente, em um único exemplar de B. biporus examinado, os testículos tinham tamanhos iguais.

Estas diferenças podem estar relacionadas ao ciclo reprodutor dos indivíduos, que sofrem modificações sazonais em suas respectivas gônadas. Bons \& SAINT Girons (1963) \& GIL et al. (1994) observaram que, na primavera, um aumento máximo no tamanho dos testículos em relação à massa corpórea verificava-se nos espécimes de $B$. cinereus e $T$. wiegmanni examinados ao longo do ano, sugerindo a ocorrência de um ciclo espermatogênico vernal. 
A ausência de dados precisos de coleta, relativos aos espécimes examinados neste estudo, impede maiores inferências a respeito do tamanho das gônadas, presença de folículos e uma possível relação com o período estacional.

Os rins, nos Amphisbaenia, posicionam-se lado a lado na porção caudal do corpo, conforme os resultados mostrados neste estudo e naqueles realizados por Crook \& Parsons (1980) e Navega-Gonçalves \& Souza (2001). O mesmo arranjo é descrito para a maioria dos lagartos (H. Fox 1977) e, a assimetria dos rins relatada no lagarto alongado Lialis burtonis Gray, 1835 (Pygopodidae) (Underwood 1957) deve-se ao maior comprimento atingido pelo rim direito, que por esta razão posiciona-se cranialmente em relação ao esquerdo, da mesma forma que foi observado, neste estudo, em alguns dos espécimes examinados, nos quais um dos rins pode ser maior que o outro. Em serpentes, no entanto, verifica-se o deslocamento em sentido cranial do rim direito em relação ao esquerdo (O'DONoGHuE 1912, Bradgon 1953, Lécuru-Renous \& Platel 1970, H. Fox 1977, Gomes et al. 1989, Gomes \& PuORTo 1993).

O canal alimentar sofre modificações em seu diâmetro, de acordo com a presença do alimento em seu interior, o que provoca variações em sua posição na cavidade pleuroperitoneal, entre os espécimes. Estas variações são particularmente notáveis com relação ao intestino delgado, cuja mobilidade provoca seu deslocamento. A ocorrência de deslocamento ou rotação de vísceras, assim como de intussuscepção intestinal podem estar relacionadas com a forma de captura, manipulação, eutanásia ou fixação do animal. Estas observações mostram a importância da utilização de anestésico antes da fixação do animal, para evitar movimentos decorrentes do estresse e dor (NAVEGa-GonÇAlves \& SOUZA 2003).

Este estudo mostrou que não é possível identificar os limites entre o esôfago e o estômago através do exame externo do canal alimentar. Embora um súbito alargamento do canal alimentar fosse conspícuo em alguns espécimes, este poderia ser provocado pela presença de alimento, conforme mencionado também por Crook \& Parsons (1980) nos anfisbenídeos $A$. darwini, L. microcephalum e Z. quadrifrons assim como no rineurídeo $R$. floridana. O estudo do canal alimentar de $A$. vermicularis e L. microcephalum mostrou que nem mesmo o exame do relevo da mucosa dos referidos órgãos propicia uma indicação precisa dos seus limites (Navega-Gonçalves \& Souza 2003).

A região cranial do intestino delgado pode apresentar uma câmara mais ou menos alargada, como observado, de forma mais conspícua em A. vermicularis e L. microcephalum (NAvEGAGonçalves \& Souza 2003). Esta região foi denominada de ceco duodenal por Crook \& PARsons (1980) e caracterizada como um divertículo do intestino delgado, que se projeta cranialmente ao piloro, em posição ventral e à direita deste. No entanto, a presença do alimento nesta região também pode provocar um aumento no diâmetro da mesma, tornando-a mais evidente em alguns espécimes do que em outros.
Um ceco cólico no intestino grosso está presente em todas as espécies examinadas neste estudo e, foi observado também nos anfisbênios estudados por Crook \& PARsons (1980) e por Navega-Gonçalves \& Souza $(2001,2003)$, facilitando o estabelecimento dos limites entre o intestino delgado e o grosso. As variações mencionadas com relação às dimensões do ceco cólico poderiam ser causadas por conteúdo alimentar, conforme sugerido para o ceco duodenal. Considerações sobre a morfologia do canal alimentar e sua relação com os hábitos alimentares dos anfisbênios foram feitas por NAVEGA-GoNÇALVES \& Souza (2003).

Interessantes são as diferenças encontradas entre os comprimentos dos lobos hepáticos direito e esquerdo. Nas seis espécies estudadas, o lobo direito do fígado apresenta-se maior que o esquerdo, com grandes variações intra e interespecíficas. Nos anfisbenídeos C. leucura, C. rondoense, M. capensis, $Z$. quadrifrons, L. microcephalum, A. kingii, A. alba e A. darwini (Crook \& Parsons 1980); em Bronia braziliana Gray, 1865 (Beddard 1905) e em A. darwini (De Carlo 1957) o lobo direito do fígado é também mais longo que o esquerdo. No entanto, no único espécime de $A$. manni observado por Crook \& PARsons (1980) o lobo esquerdo do fígado é ligeiramente maior que o direito. Nos seis espécimes de A. mertensi examinados por NAvega-Gonçalves \& Souza (2001), o lobo esquerdo ultrapassava o direito em comprimento enquanto em quatro deles ocorreu o inverso e, em apenas um exemplar os lobos apresentavam o mesmo tamanho. Nos trogonofídeos A. anguliceps e D. zarudnyi o lobo direito do fígado é também mais longo que o esquerdo, enquanto em um espécime de T. wiegmanni ocorre o contrário. No bipedídeo B. biporus (um espécime examinado) o lobo direito é mais longo e em $B$. canaliculatus (um espécime examinado) o esquerdo é ligeiramente maior (Crook \& PArsons 1980).

De acordo com Crook \& Parsons (1980) um ou ambos lobos hepáticos podem ser subdivididos secundariamente, como foi observado em B. canaliculatus e B. cinereus. Em A. darwini o lobo esquerdo é geralmente subdividido em lobos menores (DE CARLo 1957). Entre as espécies consideradas neste estudo, apenas $B$. bedai, apresenta o fígado recortado, dando origem a sublobos.

Uma possível explicação para estas diferenças foi sugerida por Romer \& PARsons (1985). Segundo os autores, as particularidades quanto ao arranjo e disposição dos lobos hepáticos variam grandemente de espécie para espécie e mesmo em indivíduos da mesma espécie, uma vez que o fígado acomoda a sua forma àquela das outras vísceras, expandindo-se em qualquer parte da cavidade do corpo não utilizada por outras vísceras. Sendo assim, é possível inferir que o comprimento maior alcançado pelo lobo direito do fígado, na maioria das espécies citadas, esteja associado à presença do pulmão (esquerdo) no antímero esquerdo da cavidade.

A bexiga urinária, presente em todos os espécimes considerados neste estudo, foi observada também nos anfisbenídeos A. alba, A. darwini, A.manni, A. kingii, L. microcephalum e $M$. 
capensis estudados por Crook \& Parsons (1980) e em A. mertensi (Navega-Gonçalves \& Souza 2001). Foi observada nos bipedídeos $B$. biporus e $B$. canaliculatus; nos trogonofídeos $T$. wiegmanni e $Z$. quadrifrons; em $B$. cinereus e em $R$. floridana. No entanto, não foi identificada nos trogonofídeos A. anguliceps e D. zarudnyi, nem nos anfisbenídeos C. leucura e C. rondoense (СRook \& PARsons 1980). Como este órgão é transparente e encontra-se entre as massas de tecido adiposo, é necessário cuidado ao proceder-se à dissecação, para que o mesmo não seja retirado juntamente com o tecido adiposo.

De acordo com Romer \& PARsons (1985), a bexiga nos tetrápodes pode não apresentar uma conexão direta com os ductos renais, abrindo-se independentemente na cloaca, como foi observado nos anfisbenídeos considerados neste estudo. Os mesmos autores admitem que a bexiga urinária seja importante na conservação de água e, em alguns tetrápodes, possa estar envolvida com a reabsorção de água impedindo a dessecação quando em ambiente terrestre. No entanto, as informações até o momento disponíveis para Amphisbaenia são incipientes para estabelecer qualquer relação entre a presença ou ausência da bexiga, os processos de economia de água do animal e o tipo de ambiente onde vive.

As variações observadas com relação à coloração e quantidade de tecido adiposo, intra e interespecificamente, foram constatadas também por Сrook \& PArsons (1980), que descreveram tecido de coloração esbranquiçada, laranja-escura, e em T. wiegmanni, observaram lobos de coloração ferrugem entre a massa acinzentada de tecido gorduroso. Estas variações podem estar associadas, por exemplo, à dieta do animal.

Os resultados obtidos com relação: ao deslocamento unilateral das gônadas, ductos associados e adrenais; à tendência a um maior tamanho alcançado pelas gônadas direitas e pelo lobo direito do fígado; à redução ou ausência do pulmão direito corroboram as proposições feitas por Gans (1975), nas quais a elongação do corpo está associada à elongação das vísceras e ao consequente deslocamento dos órgãos pares e, em alguns casos, a redução unilateral de um destes, permitindo uma melhor acomodação das vísceras em um corpo com o diâmetro relativo reduzido em relação ao comprimento total, uma tendência que se repete em outros Squamata alongados. No entanto, o deslocamento unilateral dos rins, que é conhecido nas serpentes, não foi observado nos anfisbênios.

Estudos morfológicos levando-se em conta a sintopia de órgãos internos em relação aos anéis ventrais são relativamente comuns em serpentes (Bradgon 1953, Frenkel \& Kochva 1970, Rossman et al. 1982, Gomes et al. 1989, McCraken 1991, Gomes \& Puorto 1993), no entanto, em Amphisbaenia, o primeiro estudo com este enfoque foi realizado em A. mertensi (NAVEGA-GoNÇALVES \& SOUZA 2001). Esta abordagem, embora trabalhosa, revela mais facilmente as semelhanças e diferenças encontradas, pois permite situar exatamente a posição do órgão na cavidade geral o que facilita as descrições e as comparações intra e interespecíficas.

\section{AGRADECIMENTOS}

Agradeço à Ana Maria de Souza pela orientação deste estudo durante o Programa de Doutoramento no Departamento de Zoologia, Instituto de Biociências, Universidade de São Paulo; ao CNPq pela concessão da bolsa de doutoramento; e à Camila Navega pela edição das figuras.

\section{LITERATURA CITADA}

BedDard, F.E. 1905. Some additions to the knowledge of the anatomy, principally of the vascular system, of Hatteria, Crocodilus and certain Lacertilia. Proceedings of the Zoological of Society of London 1905 (2): 461-489.

Bedriaga, J.V. 1884. Amphibaena cinerea Vand. und A. strauchi v. Bedr. erster beitrag zur kenntniss der Doppelschleichen. Archiv Fur Naturgeschichte 50 (1): 23-77.

Bons, J. \& H. SAINT-Girons. 1963. Ecologie et cycle et sexuel des amphisbéniens du Maroc. Bulletin de la Sociétè des Sciences Naturelles et Physiques du Maroc 43: 117-170.

BRADGON, D.E. 1953. A contribution to the surgical anatomy of the water snake, Natrix sipedon sipedon; the location of the visceral endocrine organs with reference to ventral scutellation. Anatomical Record 117: 145-161.

Butler, G.W. 1889. On the relations of the fat-bodies of Sauropsida. Proceedings of the Zoological Society of London 1889: 602-613.

Butler, G.W. 1895. On the complete or partial suppression of the right lung in the Amphisbaenidae and of the left lung in snakes and snake-like lizards and amphibians. Proceedings of the Zoological Society of London 1895: 691-712.

Cope, E.D. 1896. The mesenteries of the Sauria. Proceedings of the Academy of Natural Sciences 48: 308-314.

Cooper, J.E. 1992. Anaesthesia of exotic species, p. 139-151. In: A.D.R. Hilbery (Ed.). Manual of anaesthesia for small animal practice. Cheltenham, British Small Animal Veterinary Association, 156p.

Crook, M.J. \& T. Parsons. 1980. Visceral anatomy of the Amphisbaenia. Journal of Morphology 163: 99-133.

De Carlo, J.M. 1957. Consideraciones anatomo-histologicas sobre el higado y vias biliares de Amphisbaena darwini D.y B. Revista del Museo Argentino de Ciencias Naturales "Bernardino Rivadavia", Zoologia 3: 155-186.

Duvernoy, G.L. 1833. Fragments d'anatomie sur l'organisation des serpens. Annales des Sciences Naturelles 30: 113-159.

Fox, H. 1977. The urogenital system of reptiles, p. 1-157. In: C. Gans \& T.S. PARsons (Eds). Biology of the reptilia. London, Academic Press, vol. 6, 505p.

Fox, W. 1965. A comparison of the male urogenital systems of blind snakes, Leptotyphlopidae and Typhlopidae. Herpetologica 21 (4): 241-256.

FrancIS, E.T.B. 1977. Amphisbaenia: heart and arterial arches. British Journal of Herpetology 5 (8): 607-610. 
Frenkel, G. \& E. Kochva. 1970. Visceral antomy of Vipera palaestinae: an illustrated presentation. Israel Journal of Zoology 19 (3): 145-163.

Gabe, M. \& H. SaInT-Girons. 1965. Contribution a la morphologie comparée du cloaque et des glands épidermoides de la region cloacale chez les lepidosairiens. Mémoires du Museum d'Histoire Naturelle, Zoologie 33 (4): 151-292.

Gans, C. 1960. Studies on amphisbaenids (Amphisbaenia, Reptilia). 1. A taxonomic revision of the trogonophidae, and a functional interpretation of the amphisbaenid adaptative pattern. Bulletin of the American Museum of Natural History 119: 129-204.

GANS, C. 1968. Relative sucess of divergent pathways in amphisbaenian specialization. The American Naturalist 102 (926): 345-362.

Gans, C. 1969. Amphisbaenians - reptiles specialized for a burrowing existence. Endeavour 28: 146-151.

GANs, C. 1971. Studies on amphisbaenians (Amphisbaenia, Reptilia). 4. A review of the amphisbaenid genus Leposternon. Bulletin of the American Museum of Natural History 144 (6): 379-464.

GANS, C. 1974. Biomechanics: an approach to vertebrate biology. Philadelphia, J.P. Lipincott, 261p.

Gans, C. 1975. Tetrapod limblessness: evolution and functional corollaries. American Zoologist 15 (2): 455-467.

Gans, C. 1978. The characteristics and affinities of the Amphisbaenia. Transactions of the Zoological Society of London 34: 347-416.

Gans, C. 2005. Checklist and bibliografhy of the Amphisbaenia of the world. Bulletin of the American Museum of Natural History 289: 1-130.

Gans, C. \& A.A. Alexander. 1962. Studies on amphisbaenids (Amphisbaenia, Reptilia). 2. On the amphisbaenids of the Antilles. Bulletin of the Museum of Comparative Zoology 128: 65-158.

Gil, M. J.; F. Guerrero \& V. Pérez-Mellado. 1994. Clutch size and reproductive frequency of Blanus cinereus in Central Spain. Acta Biologica Cracoviensia, Series Zoologia, 36: 37-40.

Gomes, N. \& G. Puorto. 1993. Atlas anatômico de Bothrops jararaca Wied, 1824 (Serpentes: Viperidae). Memórias do Instituto Butantan 55 (Supl. 1): 69-100.

Gomes, N.; G. Puorto; M.A. Buononato \& M.F.M. Ribeiro. 1989. Atlas anatômico de Boa constrictor Linnaeus, 1758 (Serpentes, Boidae). Monografias do Instituto Butantan 2: 1-59.

JACOBSHANGEN, E. 1920. Zur morphologie des oberflächenreliefs der rumptdarmscheimhaut der reptilien. Jenaische Zeitscrift Naturwissenschaft 56: 361-430.

KeARney, M. 2003. Systematics of the Amphisbaenia (Lepidosauria: Squamata) based on morphological evidence from recent and fossil forms. Herpetological Monographs 17: 1-74.

Lécuru-Renous, S. \& R. Platel. 1970. La Vipère Aspic. Paris, DoinDeren, 153p.

LÖNNBERG, E. 1902. The morphological structure of the intestine and diet of reptiles. Kunglica Svenska Vetenskaps Akademiens Handlingar Bihang 28 (8): 3-51.

Massone, F. 1999. Anestesiologia veterinária: farmacologia e técnicas. Rio de Janeiro, Guanabara Koogan, $3^{\text {rd }}$ ed., 252p.

McCraken, H.E. 1991. The topographical antomy of snakes and its clinical applications: a preliminary report. Proceedings American Association of Zoo Veterinarians 1991: 112-119.

Miller, R.M. \& M.D. Lagios. 1970. The pancreas, p. 319-346. In: C. Gans (Ed.). Biology of the Reptilia. London, Academic Press, vol. 3, 385p.

Navega-Gonçalves, M.E.C. \& A.M. Souza. 2001. Anatomia visceral de Amphisbaena mertensi Strauch, 1881 (Reptilia, Amphisbaenia, Amphisbaenidae). Papéis Avulsos de Zoologia 41 (26): 489-518.

Navega-Gonçalves, M.E.C. \& A.M. SouZA. 2003. Morfologia externa e interna (relevo da mucosa) do canal alimentar de Amphisbaena vermicularis Wagler, 1824 e Leposternon microcephalum Wagler, 1824 (Squamata, Amphisbaenia, Amphisbaenidae). Publicações Avulsas do Instituto Pau Brasil de História Natural 7: 41-52.

O'Donoghue, C.H. 1912. The circulatory system of the common grass snake (Tropidonotus natrix). Proceedings of the Zoological of Society of London 1912 (42): 612-647.

PARsons, T.S. \& J. E. CAMERon. 1977. Internal relief of the digestive tract, p. 159-223. In: C. Gans \& T.S. Parsons (Eds). Biology of the reptilia. London, Academic Press, vol. 6, 505p.

RATHKE, H. 1857. Untersuchungen über die aortenwurzeln die von ihnen ausgehenden arterien der saurier. Denkschriften der Akademie der Wissenschaften Wien 13: 51-142.

Renous, S. 1985. The arterial arches and their interpretation in Bipes and other amphisbaenians. Journal of Morphology 184: 101-110.

Romer, A.S. \& T.S. PARsons. 1985. Anatomia Comparada dos Vertebrados. São Paulo, Atheneu, 559p.

Rossman, N.J.; D.A. Rossman \& N.K. KeIth. 1982. Comparative visceral topography of the New World snake tribe Thamnophiini (Colubridae, Natricinae). Tulane Studies in Zoology and Botany 23 (2): 123-164.

Smalian, C. 1884. Beiträge zur Anatomie der Amphisbaeniden. Zeitschrift Für Wissenschaftliche Zoologie 42 (1): 126-202.

Vidal, N.; A. Azvolinsky; C. Cruaud \& S.B.Hedges. 2008. Origin of tropical American burrowing reptiles by transatlantic rafting. Biology Letters 4: 115-118. (doi: 10.1098/rsbl.2007.0531).

Underwood, G. 1957. On lizards of the family Pygopodidae: a contribuition to the morphology and phylogeny of the Squamata. Journal of Morphology 100: 207-268.

Submitted: 14.X.2008; Accepted: 01.IX.2009.

Editorial responsibility: Ana Lúcia da Costa Prudente

ZOOLOGIA 26 (3): 511-526, September, 2009 